\section{Accuracy of Cone-Beam Computed Tomography in Measuring the Thickness of Radicular Dentin}

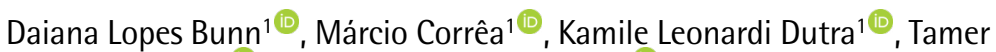 \\ Ferreira Schimdt ${ }^{1}{ }^{\circledR}$, Cleonice da Silveira Teixeira ${ }^{1 \odot}$, Lucas da Fonseca Roberti \\ Garcia $^{1}$, Eduardo Antunes Bortoluzzi' ${ }^{10}$
}

'Department of Dentistry, Endodontics Division, Health Sciences Center, UFSC - Universidade Federal de Santa Catarina, Florianópolis, SC, Brazil

Correspondence: Dr. Lucas da Fonseca Roberti Garcia, Avenida Madre Benvenuta, $\mathrm{n}^{\circ} 388$, apto. 713, 88036-500 Florianópolis, SC, Brasil. Tel: +55-48-3721-5843. e-mail:drlucas.garcia@gmail.com

\begin{abstract}
The purpose of this study was to evaluate the accuracy of Cone-Beam Computed Tomography (CBCT) in measuring radicular dentin thickness focused on intraradicular post placement planning treatment. Ten single-rooted human premolars were selected. The teeth were divided into three segments (cervical, middle and apical). The coronal face of the apical and middle sections was selected for the dentin thickness assessment; which was measured from the external root surface to the root canal wall, on the buccal, lingual, mesial, and distal surfaces of each tooth. In situ anatomical measurement was the reference standard, and the corresponding axial CBCT imaging were evaluated by the i-CAT software. The one-way ANOVA test and the Bonferroni post hoc test were applied to compare the groups ( $p>0.05)$. CBCT imaging measurements $(p=0.003)$ overestimated the radicular dentin thickness compared to the reference standard. Descriptive analysis showed that the greatest difference between the reference standard and the tomographic measurement means were $0.20 \mathrm{~mm}$. One-way ANOVA test found the statistical significant difference among group's measurements. Bonferroni correction demonstrated statistically significant difference only related lingual surface for the CBCT imaging measurements. CBCT imaging measurements overestimated the radicular dentin thickness. However, the measurement difference was clinically acceptable.
\end{abstract}

Key Words: endodontics, conebeam computed tomography, dentin, diagnostic accuracy.

\section{Introduction}

Endodontically treated teeth often present significant loss of structure that may require the use of intraradicular posts for their restoration (1). However, the post space preparation leads to additional tooth structure removal, which directly decreases the fracture resistance of the tooth (2); and accounts for the risk of root perforations during its execution (3).

The fracture resistance of restored endodontically treated teeth decreases as the amount of dentin removed increases (2). Correspondingly, the internal stress rises as the post's diameter expands (1). To minimize these effects, some principles should be followed regarding the post's placement, as well as the type, length, width, and taper of the post $(4,5)$. In general, the post's width should not exceed one-third of the overall root's width; and at least, $1 \mathrm{~mm}$ of the remaining dentin wall should be maintained $(4,5)$. Additionally, the post should be as long as possible, in order to avoid its displacement, consisting of an apical segment of 4 to 5 millimeters packed with gutta-percha to ensure adequate apical sealing $(4,5)$. Ideally, the post should be longer than the tooth crown, ending halfway between the crestal bone and the root apex (6).

The management of an endodontically treated tooth restoration requires a radicular dentin thickness assessment before attempting to place a post into the root canal; as the remaining radicular dentin is a relevant aspect associated with the long-term outcome and integrity of the tooth (7). For this reason, conventional radiography (CR) remains the most prevalent method; despite only presenting a two-dimensional (2D) view, lacking the buccal-palatal dimension, and possibly hiding curvatures and thin dentin walls on these surfaces through superimposition (8). Studies have also revealed that $C R$ could overestimate the thickness of the dentin walls, mainly in the proximal region $(8,9)$. Therefore, CR may not always be considered a reliable method for this task (9).

Currently, the use of Cone-Beam Computed Tomography ( $\mathrm{CBCT}$ ) imaging has enabled evaluation of anatomic structures in $3 \mathrm{D}$, with a higher accuracy and greater resolution than CR $(10,11)$. CBCT imaging is not indicated as a standard method for demonstration of root canal anatomy $(10,12)$. However, it may be recommended for selected cases where $C R$ provides misleading or inadequate information for planning treatment $(10,12)$. As a result, some recent studies have introduced the to evaluate dentin thickness before or after the removal of a fractured instrument $(7,13)$. However, an assessment 
focused on the intraradicular post placement planning treatment has yet to be done.

The aim of this study was to evaluate the accuracy of CBCT imaging in measuring radicular dentin thickness focused on post placement planning treatment.

\section{Material and Methods}

\section{Specimen Selection}

Following prior approval from the Research Ethics Committee (1072/11), and according to the ethical standards of the Declaration of Helsinki (1964), a prospective sample of ten single-rooted human premolars were selected, which were extracted for orthodontic reasons from patients aged 13-17 years. The sample size was calculated using the Sealed Envelope software (Sealed Envelope Ltd., https:// sealedenvelope.com/), with a minimum number of ten specimens for a power of 80\% and type I error (level of significance) of 5\%. Inclusion-criteria consisted of teeth with straight or slightly curved root canals, completed root development, only one root canal with apical diameter compatible with a size $10 \mathrm{~K}$-file, and no signs of intrapulp calcification or fracture. Radiographic examination was performed in the buccal-lingual and mesial-distal directions to confirm the anatomic findings necessary for inclusion of the teeth in the final sample.

\section{Specimen Preparation}

Coronal opening to access the root canal was performed with a spherical diamond-coated bur No. 1015 (KG Sorensen, São Paulo, SP, Brazil) in a high speed handpiece (Model 605, Kavo, Joinvile, SC, Brazil) under copious water cooling. Next, the root canal length was determined by inserting a size $10 \mathrm{~K}$-file (Dentsply Maillefer, Ballaigues, Switzerland) into the canal until the tip was seen in the apical foramen. Root canal cleaning was performed with a size $15 \mathrm{~K}$-file throughout its entire length, with smooth movements and irrigation with 5.25\% sodium hypochlorite solution (Rio Química, São José do Rio Preto, SP, Brazil), using a 30-gauge needle coupled to a $5 \mathrm{~mL}$ plastic syringe (NaviTip, Ultradent Products Inc., South Jordan, UT, USA).

Cross sections which divided the root into three segments (cervical, middle and apical) were made by drawing three perpendicular lines on the outer root surface. The first line crossed the cementoenamel junction; the second crossed exactly $5 \mathrm{~mm}$ from the root apex; and the third crossed right in the middle of the first two lines (Fig.1A). After, the teeth were embedded in polystyrene resin (ComFibras, Florianópolis, SC, Brazil) until the cementoenamel junction using a conical gypsum mould to ensure samples standardization (Fig. 1B and 1C). The resin-embedded samples were then coupled to a metallographic cutter
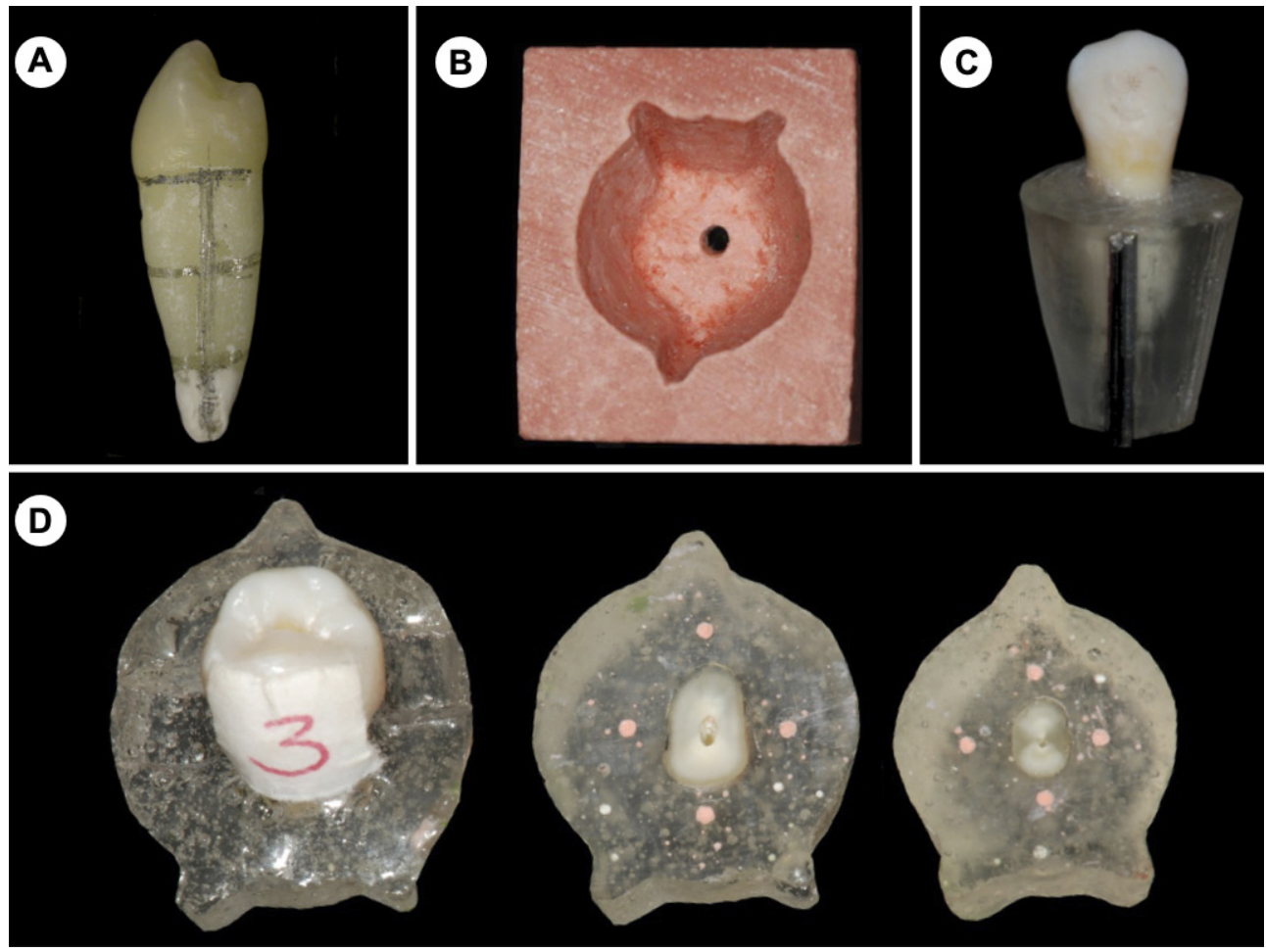

Figure 1. A: Three perpendicular lines on the outer root surface sectioning the root into three segments (cervical, middle and apical). B: Conical gypsum model. C: Teeth embedded in polystyrene resin. D: Resin-embedded samples horizontally sectioned in the previously created lines, showing tiny cavities filled with gutta-percha corresponding to the buccal, lingual, mesial and distal surfaces 
(Isomet 1000, Buehler, Lake Bluff, IL, USA), and sectioned horizontally using a double-faced diamond disk (Buehler) of $0.5 \mathrm{~mm}$ thickness in the previously created lines (Fig. 1D). This procedure allowed the visualization of the teeth through the resin transparency, enabling the reassembly of the root sections in their original position, and serving as a guide for the imaging acquisition.

\section{Anatomical Measurements (Reference Standard)}

The coronal face of the apical and middle sections were selected for the dentin thickness assessment. On those faces, tiny cavities were created in the resin, corresponding to the buccal, lingual, mesial and distal surfaces, with the aid of a size $06 \mathrm{~K}$-file (Dentsply Maillefer). Next, the cavities were filled with gutta-percha. The created cavities allowed orientation lines to be created, connecting buccallingual and mesial-distal points, thus standardizing the measurement. The thickness of the radicular dentin was measured from the external root surface to the root canal wall, on the buccal, lingual, mesial and distal surfaces of each tooth. This anatomical measurement was performed from each coronal face of the apical and middle sections of each tooth along with a digital micrometer (Starrett, 727,

s Itu, SP, Brazil), by two previously calibrated examiners, with a good average level of inter-rater agreement (kappa=0.82), and it was used as a reference standard.

\section{CBCT Imaging Measurements}

In order to perform the CBCT imaging measurements, the teeth sections were reassembled and adapted to the table of the CBCT scanner (i-CAT Cone Beam 3D, Dental Imaging System, Salt Lake City, UT, USA) set at $120 \mathrm{kV}$, valve current $37.07 \mathrm{~mA}$, and an exposure time of $26.9 \mathrm{~s}$. A FOV of $5.6 \mathrm{~cm}$ in height $x 16 \mathrm{~cm}$ in diameter was applied, and a voxel size of $0.2 \mathrm{~mm}$ was generated. The images obtained were converted into a Digital Imaging and Communications in Medicine (DICOM) format and rendered into avolumetric image using the equipment software itself (i-CAT view software, Imaging Sciences International, USA) (Fig. 2). The corresponding axial imaging of the previous anatomical measurements were evaluated 3 times with a 1-week interval using the i-CAT software by a blinded and previously calibrated dental radiologist, with experience in dentomaxillofacial tomographic imaging. The calibration consisted of measuring 05 sections of a pilot study tooth in triplicate at 2-time intervals of 30 days between them. The average results after the 2 periods were evaluated by using kappa statistics to check for intraobserver reproducibility. The value obtained for kappa was 0.87 , considered almost perfect.

Moreover, in the first period, the tomographic measurements performed by the examiner were compared with the anatomical measurements (gold standard) previously performed, resulting in a hit rate of $98 \%$, encompassing the four surfaces of each section.

\section{Statistical Analysis}

The data had a normal distribution (The Shapiro-Wilk test, $p>0.05$ ) and homogeneity of variance (The Levene test, $p>0.05$ ). The radicular dentin thickness assessment was compared between the reference standard and CBCT imaging measurements. Additionally, the radicular dentin thickness measurements of the four anatomical surfaces (buccal, lingual, mesial, and distal) in each radicular section (middle and apical third) were compared. The one-way ANOVA test was initially applied to the data and the Bonferroni post hoc test was used to identify which of the pair groups differed $(p>0.05)$.

\section{Results}

In generall, the CBCT imaging measurements $(p=0.003)$
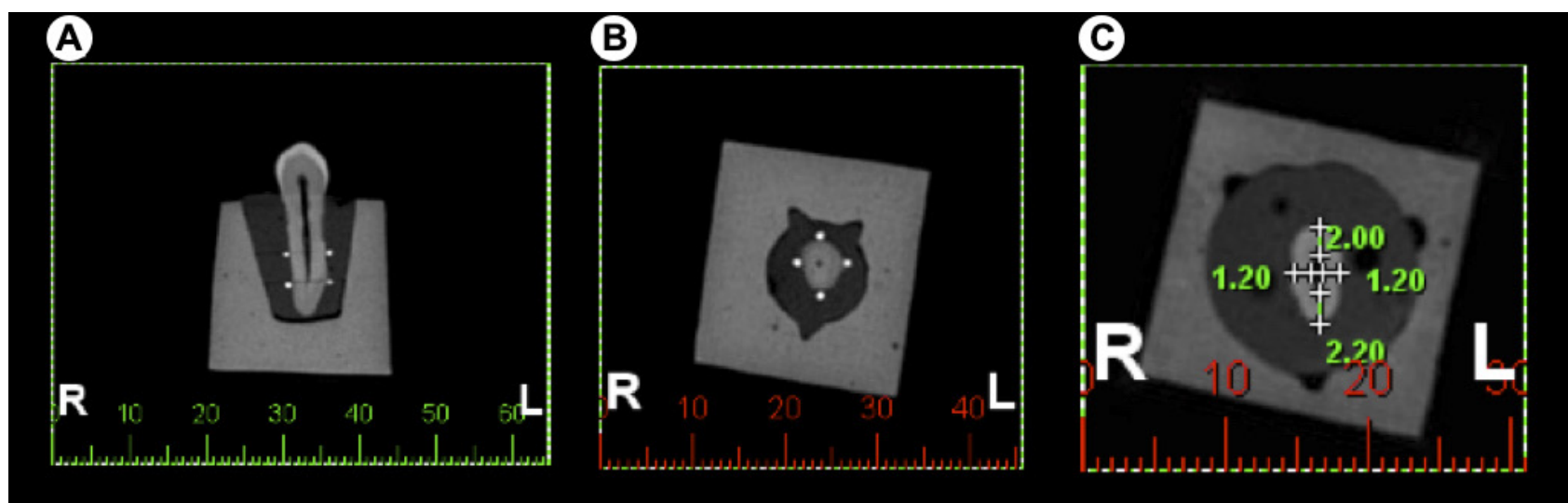

Figure 2. CBCT images obtained with the i-CAT software. A: The coronal plane. B: The axial plane. C: The radicular dentin thickness measurements of the four anatomic surfaces (buccal, lingual, mesial, and distal) in apical radicular section assessed by the iCAT software. Different lowercase letters in the columns mean statistically significant difference. Different uppercase letters in the rows mean statistically significant difference. 
overestimated the radicular dentin thickness compared to the reference standard (Table 1). However, when the different anatomical surfaces were considered, CBCT significantly overestimated the reference standard only in the lingual surface $(p=0.008)$, while the buccal, mesial, and distal surfaces did not demonstrate statistically significant difference (Table 2). For the apical third, regardless of the radicular surface evaluated, the CBCT imaging measurements did not demonstrate statistically significant difference in comparison with the reference standard $(p=0.120)$ (Table 3$)$.

With respect to the comparison of the radicular dentin thickness measurements among the anatomical surfaces (buccal, lingual, mesial, and distal) in each radicular section (middle and apical third), the results demonstrated that, in the middle third, the thickness of the buccal and lingual walls were statistically similar between them, and the thicknesses of the mesial and distal walls were statistically similar when compared to the buccal and lingual walls, regardless of the measurement method used (Table 2). In the apical third, the lingual wall was thicker than the others, however, there was a statistical difference only in the comparison with the mesial $(p=0.000194)$ and distal ( $p=0.000093$ ) walls (Table 3 ).

The mean values of radicular dentin thickness for each of the four anatomic surfaces evaluated (buccal, lingual, mesial, and distal) in each radicular section (middle and apical third) were detailed in Table 4.

Table 1. Radicular dentin thickness (mm) comparison between the different measurement methods performed

\begin{tabular}{lccccc}
\hline Method & $\mathrm{N}$ & Minimum & Maximum & Mean & $\begin{array}{c}\text { Standard } \\
\text { deviation }\end{array}$ \\
\hline $\begin{array}{l}\text { Reference } \\
\text { standard }\end{array}$ & 80 & 0.98 & 2.86 & $1.7115 \mathrm{a}$ & 0.42475 \\
CBCT & 80 & 1.00 & 3.20 & $1.7925 \mathrm{~b}$ & 0.49447 \\
\hline
\end{tabular}

$\mathrm{N}=$ sample size. Different lowercase letters mean statistically significant difference.

Table 2. Radicular dentin thickness (mm) comparison between the measurement methods performed, considering the different anatomical surfaces

\begin{tabular}{lccc}
\hline $\begin{array}{l}\text { Radicular } \\
\text { section }\end{array}$ & $\begin{array}{c}\text { Root } \\
\text { surface }\end{array}$ & $\begin{array}{c}\text { Reference } \\
\text { standard }\end{array}$ & CBCT \\
\hline \multirow{3}{*}{ Middle } & Buccal & $2.043 \mathrm{aA}$ & $2.140 \mathrm{abA}$ \\
& Lingual & $2.324 \mathrm{aB}$ & $2.520 \mathrm{aA}$ \\
& Mesial & $1.475 \mathrm{aA}$ & $1.540 \mathrm{bA}$ \\
& Distal & $1.396 \mathrm{aA}$ & $1.380 \mathrm{bA}$ \\
\hline
\end{tabular}

Different lowercase letters in the columns mean statistically significant difference. Different uppercase letters in the rows mean statistically significant difference.

\section{Discussion}

The accuracy of $\mathrm{CBCT}$ imaging was investigated in this study with respect to measuring radicular dentin thickness, primarily focused on intraradicular post-placement planning treatment. The post-placement should be cautiously planned in order to avoid root perforations or excessive root weakening, which may compromise tooth longevity $(2,3,14)$. Consequently, the preparation of the post space requires previous accurate measurements of the remaining radicular dentin thickness $(4-6,15)$.

In thisstudy, the radicular dentin thickness of mandibular premolars was measured in the middle and apical thirds ( $5 \mathrm{~mm}$ from the apex). For the reference standard, crosssections of the tooth were measured in situ by a millimeterscale. Tomographic images of the same regions were evaluated by the i-CAT software itself. By comparing the tomographic measurements with the reference standard, an overestimation of $4.7 \%$ was observed. In particular, only one surface (lingual of the middle third) was overestimated by the CBCT imaging measurement. Given the results, the CBCT imaging measurement method displayed a proper performance; establishing that the use of the software indicated by the tomograph manufacturer seems to be an adequate tool to assess the dentin thickness.

As for the thickness overestimation detected, the mean values shown in Table 4 revealed that the greatest difference between the reference standard and the $\mathrm{CBCT}$ imaging measurement means was $0.20 \mathrm{~mm}$. These differences in measurements may have occurred for two reasons. Firstly, there may have been an overestimation of the lingual surface due to the partial volume artifact as a function of the size of the voxel used, noting that the CBCT back-projection reconstruction process is not distorted, and this imaging modality has a 1:1 measurement in all circumstances (18). Second by the inaccuracy of the

Table 3. Radicular dentin thickness $(\mathrm{mm})$ comparison of each measurement method and anatomical surface obtained in the apical third

\begin{tabular}{lcc}
\hline $\begin{array}{l}\text { Radicular } \\
\text { Section }\end{array}$ & Measurement Methods & Mean \\
\hline & Reference standard & $1.614 \mathrm{a}$ \\
& CBCT & $1.690 \mathrm{ab}$ \\
Apical & Buccal & $1.759 \mathrm{ab}$ \\
& Lingual & $2.097 \mathrm{a}$ \\
& Mesial & $1.440 \mathrm{~b}$ \\
& Distal & $1.406 \mathrm{~b}$
\end{tabular}

Different lowercase letters mean statistically significant difference. 
examiner using the computer mouse; which has been previously demonstrated that the average precision error between the on-screen cursor and the mouse displacement was $0.018 \mathrm{~mm}^{2}$ (16-18). This measurement error may not be suitable for precise control applications, however, this may be precise enough for a successful CBCT linear measurements, as representing less than a voxel size currently used $(13,16-18)$. Further studies are needed to clarify the clinical relevance of these narrow ranges, using another CBCT scanner with a smaller voxel size may allow a more accurate measurement (18).

On the other hand, previous studies reported that when the radicular dentin thickness of upper and lower premolars was assessed using CR, overestimations of 25\% and 35\% were observed, respectively $(9,19)$. Further studies should attempt to assess the accuracy of CR and CBCT using the same sample, enabling reliable comparisons among them.

To date, conventional radiography (CR) remains the most used method for post placement planning treatment; even with a significantly known overestimation of the dentin thickness due to its 2D nature overlapping the anatomic surfaces (8). Moreover, lacking the buccal-palatal dimension, CR possibly hides curvatures and thin dentin walls on these surfaces, which may be a substantial risk for the post place $(7,19)$. Accordingly, the use of CBCT imaging may be considered to achieve more reliable measurements of radicular dentin thickness due to its $3 \mathrm{D}$ nature with images of higher accuracy and resolution than $C R(10,11)$. Despite that, CBCT imaging is not recommended as a standard method for demonstration of root canal anatomy; it may be recommended only for selected cases where CR provides misleading or inadequate information for planning treatment (12). Although, patients who already have the exam for other treatment reasons can benefit, increasing the performance of treatment options through extracting more information from CBCT imaging.

Currently, some studies have introduced CBCT imaging to evaluate dentin thickness before and after fractured instrument removal $(7,13)$, or before and after root canal preparation $(20,21)$. However, no comparisons with a reference standard were reported, which prevents accuracy from being determined. Aside from Asgary et al. (22), which assessed the diagnostic accuracy of CBCT in measuring the thickness of canal walls and found a high correlation

Table 4. Detailed descriptive analysis of radicular dentin thickness (mm)

\begin{tabular}{|c|c|c|c|c|c|c|c|c|}
\hline Root Section & Root Surface & Methods & $\mathrm{N}$ & Mean & SD & SEM & Minimum & Maximum \\
\hline \multirow{9}{*}{ Middle } & \multirow{2}{*}{ Buccal } & Reference standard & 10 & 2.04 & 0.28 & 0.08 & 1.66 & 2.49 \\
\hline & & $\mathrm{CBCT}$ & 10 & 2.14 & 0.34 & 0.11 & 1.60 & 2.60 \\
\hline & \multirow{2}{*}{ Lingual } & Reference standard & 10 & 2.32 & 0.26 & 0.08 & 1.87 & 2.86 \\
\hline & & $\mathrm{CBCT}$ & 10 & 2.52 & 0.32 & 0.10 & 2.20 & 3.20 \\
\hline & & & & & & & & \\
\hline & \multirow{2}{*}{ Mesial } & \multirow{2}{*}{$\begin{array}{c}\text { Reference standard } \\
\text { CBCT }\end{array}$} & 10 & 1.48 & 0.54 & 0.17 & 0.98 & 2.86 \\
\hline & & & 10 & 1.54 & 0.19 & 0.60 & 1.20 & 1.80 \\
\hline & \multirow{2}{*}{ Distal } & \multirow{2}{*}{$\begin{array}{l}\text { Reference standard } \\
\text { CBCT }\end{array}$} & 10 & 1.40 & 0.18 & 0.06 & 1.16 & 1.65 \\
\hline & & & 10 & 1.38 & 0.26 & 0.08 & 1.00 & 1.80 \\
\hline \multirow{9}{*}{ Apical } & \multirow{2}{*}{ Buccal } & \multirow{2}{*}{$\begin{array}{c}\text { Reference standard } \\
\text { CBCT }\end{array}$} & 10 & 1.66 & 0.28 & 0.09 & 1.06 & 1.99 \\
\hline & & & 10 & 1.76 & 0.31 & 0.10 & 1.20 & 2.20 \\
\hline & \multirow{2}{*}{ Lingual } & \multirow{2}{*}{$\begin{array}{l}\text { Reference standard } \\
\text { CBCT }\end{array}$} & 10 & 1.98 & 0.46 & 0.15 & 1.27 & 2.86 \\
\hline & & & 10 & 2.16 & 0.42 & 0.13 & 1.40 & 2.80 \\
\hline & & & & & & & & \\
\hline & \multirow{2}{*}{ Mesial } & \multirow{2}{*}{$\begin{array}{l}\text { Reference standard } \\
\text { CBCT }\end{array}$} & 10 & 1.43 & 0.18 & 0.06 & 0.98 & 1.67 \\
\hline & & & 10 & 1.46 & 0.21 & 0.07 & 1.20 & 1.80 \\
\hline & \multirow{2}{*}{ Distal } & Reference standard & 10 & 1.40 & 0.18 & 0.06 & 1.16 & 1.65 \\
\hline & & CBCT & 10 & 1.38 & 0.26 & 0.08 & 1.00 & 1.80 \\
\hline
\end{tabular}

$\mathrm{N}$ : sample size; $\mathrm{SD}=$ standard deviation; $\mathrm{SEM}=$ standard error mean. 
existed between CBCT and the measurements obtained using a stereo-microscope as the reference standard. These authors established CBCT as an acceptable diagnostic tool for the measurement of canal wall thickness (22).

It is important to point out that, in this study, the samples were not submitted to mechanical preparation of the root canal before the imaging acquisition, thus the radicular dentin was not worn out. Although, minimum values of thickness were revealed as equal to $1.0 \mathrm{~mm}$ or less. This raises the attention of clinicians, as in a realclinical situation, even lower values should be expected in endodontic treated teeth $(23,24)$; and the post-placement principle of maintenance with at least $1 \mathrm{~mm}$ of the remaining dentin should be unfeasible $(6,15)$.

In endodontic practice, many cases that require CBCT are endodontically treated teeth (25) According to Dutra et al. (25), the presence of filling material (gutta-percha/ sealer) generates a low-beam hardening artifact which do not compromise the proper assessment of anatomical features, as vertical root fractures. Conversely, Vizzotto et al. (10) reported that root canal filling removal prior to CBCT analysis consistently eliminates artefact production, allowing the use of the $0.3-\mathrm{mm}$ voxel protocol, which has an adequate diagnostic performance with lower radiation dose to patient. Prior to post-placement planning using CBCT analysis, clinicians should consider the removal of the entire root canal filling, or part of it (2/3), to perform a more accurate analysis of the thickness of radicular dentin (10). For this reason, in the present study, non-filled root canals were used to perform the CBCT analysis.

Considering the limitations of this study, it can be concluded that $\mathrm{CBCT}$ overestimated the radicular dentin thickness by $0.20 \mathrm{~mm}(8 \%)$. Nevertheless, such measurement difference was clinically acceptable and demonstrate a proper performance of CBCT diagnostic accuracy before intraradicular post-placement. In addition, it is feasible to state that further studies are needed using a limited FOV and a smaller voxel size.

\section{Resumo}

0 objetivo deste estudo foi avaliar a precisão da Tomografia Computadorizada de Feixe Cônico (TCFC) na mensuração da espessura da dentina radicular no planejamento de tratamento envolvendo a cimentação de pinos intrarradiculares. Dez pré-molares humanos unirradiculares foram selecionados. Os dentes foram divididos em três segmentos (cervical, médio e apical). A face coronal dos terços apical e médio foi selecionada para a avaliação da espessura da dentina; que foi medida a partir da superfície externa da raiz até a parede do canal radicular, nas superfícies vestibular, lingual, mesial e distal de cada dente. A medida anatômica in situ foi o padrão de referência, e a imagem de TCFC axial correspondente foi avaliada pelo software i-CAT. 0 teste de 1-fator ANOVA e o teste post hoc de Bonferroni foram aplicados para comparar os grupos $(p>0,05)$. As medidas de imagem da TCFC $(p=0,003)$ superestimaram a espessura da dentina radicular em comparação a referência padrão. $\mathrm{A}$ análise descritiva mostrou que a maior diferença entre a referência padrão e a medida tomográfica foi de $0,20 \mathrm{~mm}$. 0 teste ANOVA encontrou a diferença de significância estatística entre as medidas do grupo. A correção de Bonferroni demonstrou diferença estatisticamente significante apenas relacionada às medidas de imagem da TCFC. A medida de imagem da TCFC superestimou a espessura da dentina radicular. No entanto, a diferença de medição foi clinicamente aceitável.

\section{References}

1. Robbins JW. Guidelines for the restoration of endodontically treated teeth. J Am Dent Assoc 1990;120:558-562.

2. Tang $W, W u Y$, Smales RJ. Identifying and reducing risks for potential fractures in endodontically treated teeth. J Endod 2010;36:609-617.

3. Alomari $\mathrm{QD}$, Barrieshi KM, Al-Awadhi SA. Effect of post length and diameter on remaining dentine thickness in maxillary central and lateral incisors. Int Endod J 2011;44:956-966.

4. Schwartz RS, Robbins JW. Post placement and restoration of endodontically treated teeth: a literature review. J Endod 2004;30:289301.

5. Cheung W. A review of the management of endodontically treated teeth. Post, core and the final restoration. J Am Dent Assoc 2005;136:611-619.

6. Ricketts DN, Tait CM, Higgins AJ. Tooth preparation for post-retained restorations. Br Dent J 2005;198:463-471.

7. Xu J, He J, Yang 0 , Huang D, Zhou X, Peters OA, et al. Accuracy of conebeam computed tomography in measuring dentin thickness and its potential of predicting the remaining dentin thickness after removing fractured instruments. J Endod 2017;43:1522-1527.

8. Patel S, Dawood A, Whaites E, Pitt Ford T. New dimensions in endodontic imaging: part 1. Conventional and alternative radiographic systems. Int Endod J 2009;42:447-462.

9. Souza EM, Bretas RT, Cenci MS, Maia-Filho EM, Bonetti-Filho I. Periapical radiographs overestimate root canal wall thickness during post space preparation. Int Endod J 2008;41:658-663.

10. Vizzotto MB, Silveira PF, Arús NA, Montagner F, Gomes BP, da Silveira $\mathrm{HE}$. CBCT for the assessment of second mesiobuccal (MB2) canals in maxillary molar teeth: effect of voxel size and presence of root filling. Int Endod J 2013;46:870-876.

11. AAE and AAOMR joint position statement: use of cone beam computed tomography in endodontics 2015 update. J Endod 2015;41:1393-1396.

12. SEDENTEXCT. Radiation protection: cone beam ct for dental and maxillofacial radiology. Evidence based guidelines. Available at: http:// www.sedentexct.eu/files/radiation_protection_172.pdf. Accessed September 2, 2020.

13. Costa EDD, Queiroz PM, Santaella GM, Capelozza ALA, Ambrosano GMB, Freitas DQ. Influence of scan mode (partial/full rotations) and FOV size in the formation of artefacts in cone beam CT. Dentomaxillofac Radiol 2019;48:20180340.

14. Kuttler S, McLean A, Dorn S, Fischzang A. The impact of post space preparation with Gates-Glidden drills on residual dentin thickness in distal roots of mandibular molars. J Am Dent Assoc 2004;135:903-909.

15. Morgano SM, Rodrigues AH, Sabrosa CE. Restoration of endodontically treated teeth. Dent Clin North Am 2004;48:vi,397-416.

16. $\mathrm{Ng}$ TW. The optical mouse as a two-dimensional displacement sensor. Sensors and Actuators A 2003;107:21-25.

17. $\mathrm{Ng}$ TW. The optical mouse for vibratory motion sensing. Sensors and Actuators A 2004;116:205-208.

18. Schulze $R$, Heil $U$, Gross D, Bruellmann DD, Dranischnikow $E$, Schwanecke $U$, et al. Artefacts in CBCT: a review. Dentomaxillofac Radiol 2011;40:265-273.

19. Raiden G, Koss S, Costa L, Hernandez JL. Radiographic measurement of residual root thickness in premolars with post preparation. J Endod 2001;27:296-298.

20. Elnaghy AM, Elsaka SE. Evaluation of root canal transportation, centering ratio, and remaining dentin thickness associated with ProTaper Next instruments with and without glide path. J Endod 2014;40:2053-2056.

21. Flores CB, Montagner F, Gomes BP, Dotto GN, da Silva Schmitz M. 
Comparative assessment of the effects of Gates-Glidden, Largo, LAAxxess, and New Brazilian Drill CPdrill on coronal pre-enlargement: cone-beam computed tomographic analysis. J Endod 2014;40:571-574.

22. Asgary $S$, Nikneshan $S$, Akbarzadeh-Bagheban A, Emadi N. Evaluation of diagnostic accuracy and dimensional measurements by using CBCT in mandibular first molars. J Clin Exp Dent 2016;8:e1-e8.

23. Katz A, Wasenstein-Kohn S, Tamse A, Zuckerman O. Residual dentin thickness in bifurcated maxillary premolars after root canal and dowel space preparation. J Endod 2006;32:202-205.

24. Pilo R, Shapenco E, Lewinstein I. Residual dentin thickness in bifurcated maxillary first premolars after root canal and post space preparation with parallel-sided drills. J Prosthet Dent 2008;99:267-273.

25. Dutra KL, Pacheco-Pereira C, Bortoluzzi EA, Flores-Mir C, Lagravere MO, Corrêa M. Influence of intracanal materials in vertical root fracture pathway detection with cone-beam computed tomography. J Endod 2017:43:1170-1175.

Received August 2, 2019 Accepted April 2, 2020 